\title{
Multiple groundwater dating conducted at Mizunami URL
}

\author{
T. HASEGAWA ${ }^{1 *}$, K. NAKATA $^{1}$, Y. TOMIOKA ${ }^{1}$, T. OHTA ${ }^{1}$, \\ S. OKAMOTO ${ }^{1}$, K. HAMA $^{2}$, T. IWATSUKI ${ }^{2}$, \\ Y.WATANABE ${ }^{2}$
}

${ }^{1}$ Civil engineering Research Laboratory,

Central Research Institute of Electric Power Industry

(*correspondence: *t-hase@criepi.denken.or.jp)

${ }^{2}$ Tono Geoscience Center, Japan Atomic Enegy Agency

Groundwater dating using isotopes and noble gases is one of the most promising method to evaluate very old groundwater. Dating groundwater with multiple methods can provide the reliability of estimated age by cross-checking these results each other [1]. Mizunami area, in the middle part of Japan, there are over 10 deep boreholes, and many kinds of groundwater investigations have been conducted. On groundwater dating, ${ }^{14} \mathrm{C}$ and ${ }^{4} \mathrm{He}$ ages were consistent. The initial ${ }^{14} \mathrm{C}$ was estimated by ${ }^{4} \mathrm{He}$ accumulation and ${ }^{4} \mathrm{He}$ accumulation rate could be calibrated by ${ }^{14} \mathrm{C}$ decay [2] However, ${ }^{4} \mathrm{He}$ concentrations is affected by external flux and ${ }^{14} \mathrm{C}$ concentration has high uncertainty due to low DIC in discharge area. As a result, it is difficult to estimate groundwater age in discharge area.

Thus, groundwater samples were collected from borehole in Mizunami URL located at discharge area. ${ }^{4} \mathrm{He}$ age can be determined by considering contribution of external flux. Because ${ }^{3} \mathrm{He} /{ }^{4} \mathrm{He}$ ratio of external flux and in situ production are different and contribution of external flux can be calculated from multiple samples, which have different mixing ratio of external flux due to URL construction. ${ }^{14} \mathrm{C}$ concentration can be stabilized after pre-treatment was changed from precipitation method to gas stripping method due to eliminate atmospheric ${ }^{14} \mathrm{C}$ contamination [3]. These results show that groundwater age is about 20,000 y around URL. Moreover, $\delta \mathrm{D}$ and $\delta^{18} \mathrm{O}$ are lower than those of shallow groundwater. The recharge temperature is about $7^{\circ} \mathrm{C}$ estimated by noble gas concentrations, which is about $7^{\circ} \mathrm{C}$ lower than present annual temperature in this area. Thus, the groundwater around URL is probably recharged at glacial period. The groundwater age around Mizunami URL can be consistently determined by multiple groundwater dating methods, which are ${ }^{14} \mathrm{C},{ }^{4} \mathrm{He}, \delta \mathrm{D}, \delta^{18} \mathrm{O}$ and noble gas temperature.

This study was supported by the Japanese Ministry of Economy, Trade and Industry.

[1] Mahara et al.(2009), EPSL,287, 43-56.

[2] Hasegawa et al.(2016), GCA, 192,166-185.

[3] Nakata et al.(2016), Radiocarbon, 58, 491-503. 